Portland State University

PDXScholar

1986

\title{
Effects of stress management instruction and anxiety monitoring in adult day treatment population
}

Jack Blanton Wills

Portland State University

Follow this and additional works at: https://pdxscholar.library.pdx.edu/open_access_etds

Part of the Counseling Psychology Commons, and the Mental and Social Health Commons Let us know how access to this document benefits you.

Recommended Citation

Wills, Jack Blanton, "Effects of stress management instruction and anxiety monitoring in adult day treatment population" (1986). Dissertations and Theses. Paper 3698.

https://doi.org/10.15760/etd.5582

This Thesis is brought to you for free and open access. It has been accepted for inclusion in Dissertations and Theses by an authorized administrator of PDXScholar. Please contact us if we can make this document more accessible: pdxscholar@pdx.edu. 
AN ABSTRACT OF THE THESIS OF Jack Blanton wills for the Master of Science in Psychology presented July 31, 1986.

Title: Effects of Stress Management Instruction and Anxiety Monitoring in Adult Day Treatment Population

APPROVED BY MEMBERS OF THE THESIS COMMITTEE:

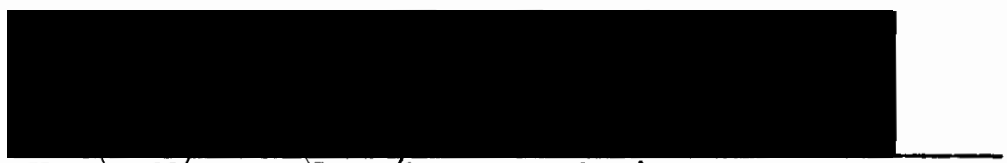

Huga Maynard, P̈h.D., Chairman
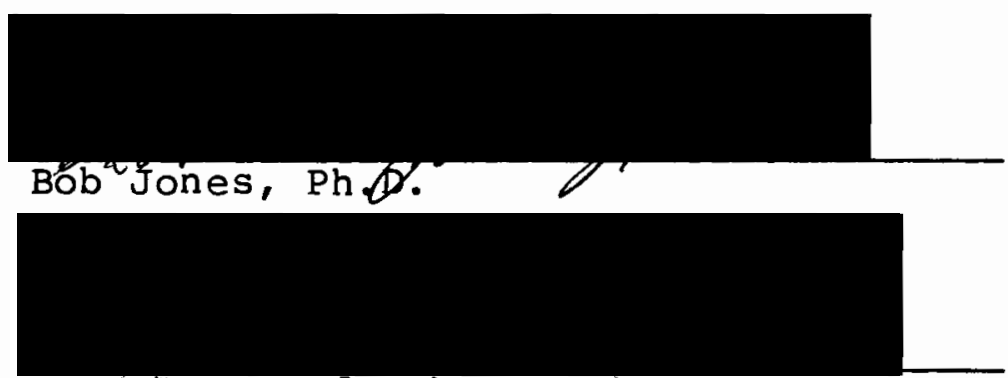

Dave Drummond, Ph.D.

This study examines the effectiveness of a particular stress management intervention with adult outpatients diagnosed as chronic schizophrenics. The setting for the study was the Portland, oregon, Veteran's Administration, Outpatient Clinic, Day Treatment center. The intervention was composed of two factors; 1) stress management training and 2) Behavior-Graph Instruction. Both of these were presented using a psychoeducational model of classroom instruction, role play, and discussion. 
The rationale for this research was twofold. One, the Day Treatment Center needed information on the efficacy of treatment within the milieu. Two, considerable scientific evidence and theoretical speculation points to stress as an important factor in psychotic episodes and hospital readmission of chronic and acute schizophrenics. These considerations are discussed in the study and the arguments for recognition of stress in schizophrenics as objective Iife events or subjective interpretation life events are presented.

The psychoeducational training took place in a group room, using a blackboard for presentation of didactic material. Twenty four male, veteran subjects were included in the sample for analysis. All treatment subjects carried a diagnosis of schizophrenia, with the exception of two diagnosed as having bi-polar affective disorder. These were excluded from analysis so the results could be applied to schizophrenics specifically.

The experimental design involved four groups of six subjects each. The two factors mentioned above were assigned to the groups as follows; (Group 1 or Manage/Chart) received training in stress management techniques (e.g. relaxation training, social network development, exercise and leisure involvement), and this group completed a behavior graph under instruction. The behavior graph (Anxiety-Mood Chart) involved the daily graphing of changes 
in mood and anxiety and these changes were related to current Iife events, (Group 2 or Chart) received instruction in and discussed the behavior chart technique, (Group 3, Manage) received instruction in stress management techniques, only, (Group 4, or Control) received no special training nor instruction. All of the above groups continued to participate in the milieu of and treatment provided by the Day Treatment Center and the Mental Health Clinic.

The treatment effects were measured by three assessment tools. The Social Stress and Functioning Inventory for Psychotic Disorders (SSFIPD), the Symptoms Check List - 90 (SCL-90), and Behavior Check List (BCL), an observation tool.

Analysis of Covariance was completed on the data and results supported the null hypothesis. No significant differences were found between the effectiveness of various group strategies in improving the dependent variables as assessed by the SSFIPD, SCL-90 or BCL. Reasons for the lack of significance are discussed and suggestions are made concerning future examination of stress management training with schizophrenics. 


\section{EFFECTS OF STRESS MANAGEMENT INSTRUCTION \\ AND ANXIETY MONITORING IN ADULT \\ DAY TREATMENT POPULATION}

by

JACK BLANTON WILLS

A thesis submitted in partial fulfillment of the requirements for the degree of

\section{MASTER OF SCIENCE \\ in \\ PSYCHOLOGY}

Portland State University 
TO THE OFFICE OF GRADUATE STUDIES AND RESEARCH:

The members of the Committee approve the thesis of Jack Blanton Wills presented July 31, 1986.

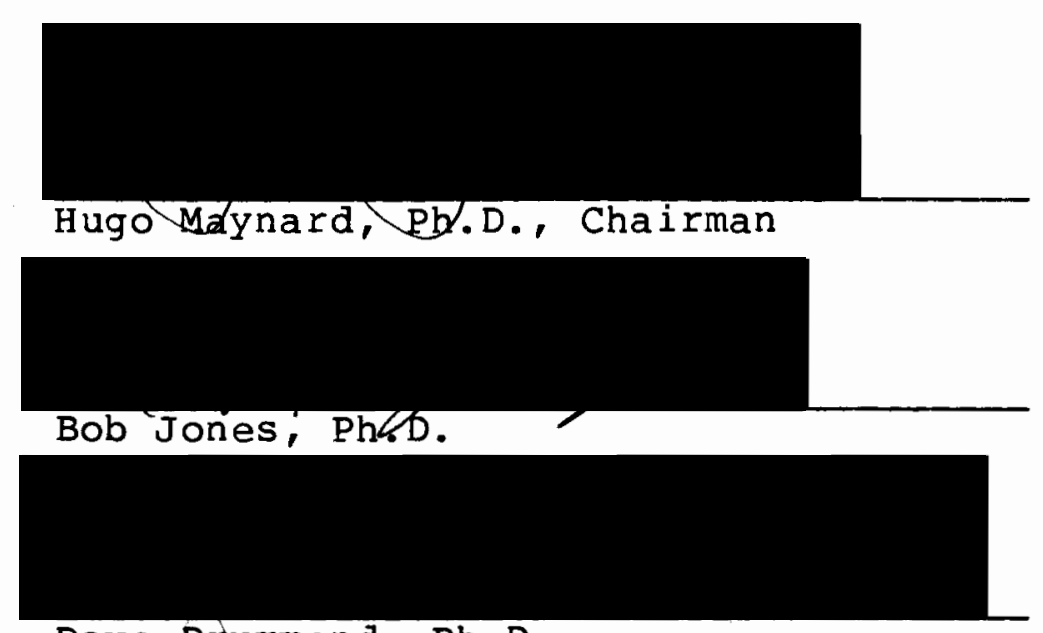

Dave Drummond, Ph.D.

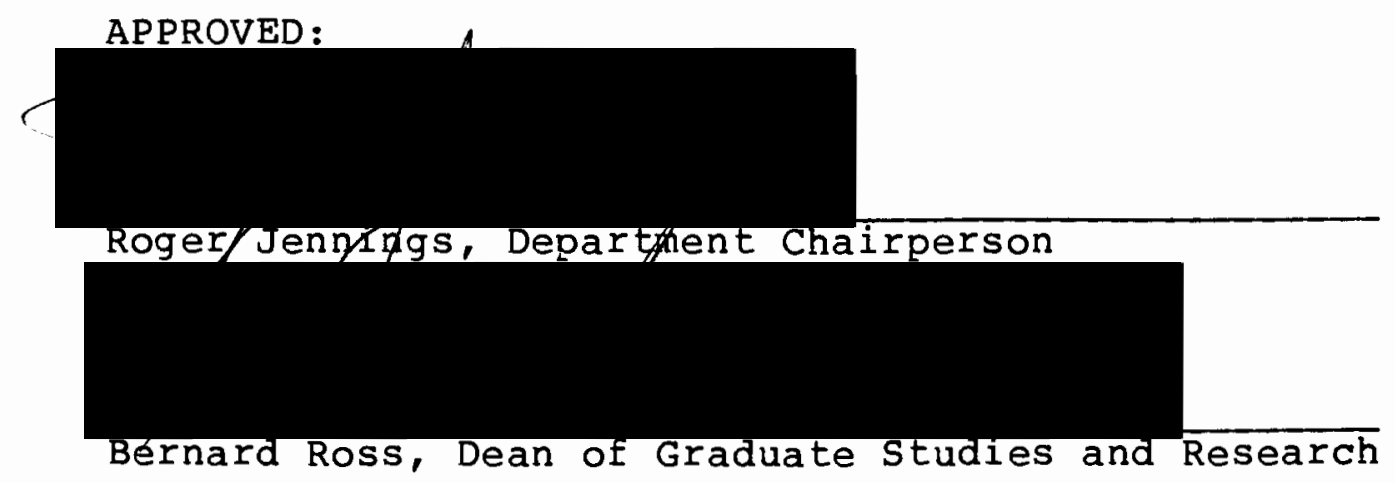




\section{ACKNOWLEDGEMENTS}

I would like to thank my committee members, Hugo Maynard, Ph.D., Chairperson, Robert Jones, Ph.D., and David Drummond, Ph.D. for their responsiveness during the final effort of my thesis. I am also grateful to the Day Treatment Center, Portland, Oregon, Veteran's Administration staff for their assistance in obtaining the data. However, most of my gratitude goes to my wife Rebecca L. Folz for her patience, encouragement and assistance during the long and sometimes discouraging process. 
TABLE OF CONTENTS

PAGE

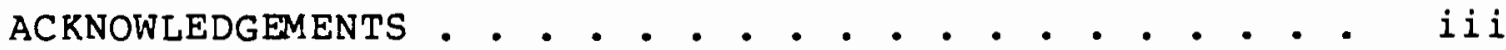

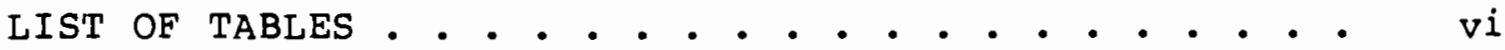

LIST OF FIGURES. • • • • • • • • • • • • • • • • • . . viii

SECTIONS

INTRODUCTION. . . . . . . . . . . . . . . . . I 1

Stress and Schizophrenia . . . . . . . 2

Stress Management Training . . . . . . . 3

Day Treatment Center Training Format . . . . 4

METHOD . • . . . . . . . . . . . . . . 10

Setting. . . . . . . . . . . . . . 10

subjects . . . . . . . . . . . . 10

procedure. . . . . . . . . . . . . . 12

RESULTS • • • • • • • • • • • • • • • . . 21

DISCUSSION. • • • . . . . . . . . . . . 34

REFERENCES . . . . . . . . . . . . . . . . . . . 45

APPENDIX A . . . . . . . . . . . . . . . . . . . 48

Group Descriptions and Outlines

APPENDIX B • . . . . . . . . . . . . . . . . . . .

Instruction Material 
PAGE

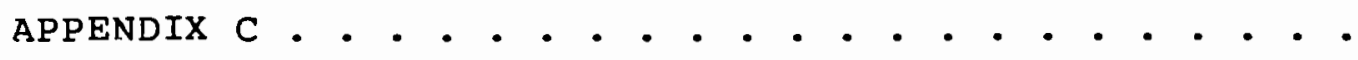

Setting Diagrams

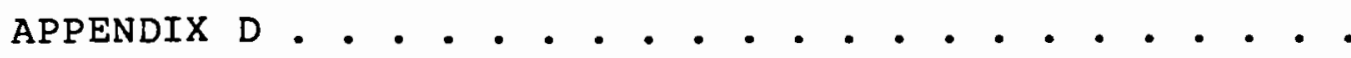

Release of Information Form 


\section{LIST OF TABLES}

TABLE

PAGE

I. Clinical Information by subject . . . . . .

II. Interrater Reliability with Cohen's Kappa Coefficients . . . . . . . . . . . .

III. Analysis of Covariance for Global Severity

Index Scale Scores (SCL-90).......

IV. Analysis of Covariance for Psychotic Scores $(\mathrm{SCL}-90)$. . . . . . . . . . . . .

V. Analysis of Covariance for Anxiety Scores $(\mathrm{SCL}-90)$. . . . . . . . . . . .

VI. Analysis of Covariance of Stress Scores

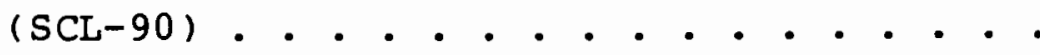

VII. Analysis of Covariance for Function Scores (SSFIPD) • . . . . . . . . . . . . . 28

VIII. Analysis of Covariance with Repeated Measures for Behavioral Observations. . . . . .

IXa. SCL-90 Global Severity Index Means and

Standard Deviations. . . . . . . . 30

IXb. SCL-90 Psychotic Scale Means and standard Deviations . . . . . . . . . . . 30

IXC. SCL-90 Cell Means and Standard Deviations for Anxiety Scale. . . . . . . . . . . 
vi i

TABLE

PAGE

Xa. Means and Standard Deviations for Function

Scale on Social Stress and Functioning

Inventory for Psychotic Disorders

(SSFIPD) • • • • • . . . . . . . . . .

32

$\mathrm{Xb}$. Means and Standard Deviations for Stress

Scale SSFIPD . . . . . . . . . . . 32

XIa. Means and Standard Deviations for Behavioral

Observations; Baseline Plus Three

Observations Occurring Three Weeks

Apart. . . . . • . . . . . . . . •

XIb. Adjusted Cell Means for Behavioral

Observations . . . . . . . . . . . . 


\section{LIST OF FIGURES}

FIGURE

PAGE

1. Experimental Design. . . . . . . . . . . 9

2a. SCL-90 Means on Global (Severity) Index. . . 35

2b. SCL-90 Means on Psychotic Scale. . . . . . 36

2c. SCL-90 Means on Anxiety Scale. . . . . . . 37

3a. SSFIPD Means for Function Scale. . . . . . 38

3b. SSFIPD Means for Stress Scale. . . . . . . 39

4. Means for Behavioral Observations Sequential

Representation. . . . . . . . . . 40 


\section{INTRODUCTION}

Several types of treatment programs have been developed recently in the mental health field to address issues of recidivism, rehabilitation, and deinstitutionalization in the chronically mentally ill population. The purposes of these outpatient programs have been to provide structure, support and training. Current treatment models include sheltered workshops, milieu clubhouses, and psycho-educational approaches.

In some respects the variety of treatment approaches raises more questions than it answers. Despite the appearance of improvement in certain aspects of the chronically mentally ill population, it is not clear what conditions are successfully affecting treatment. It remains to empirically establish the variables essential to positive change. To accomplish this, it is necessary to focus on specific aspects of each method. This study will examine the effectiveness of one psycho-educational approach .

A major component of the psycho-educational approach has been one of teaching daily living skills in a series of group sessions. The intent of these classes is to provide 
the chronic psychiatric patient with an opportunity to develop skills enabling him/her to function adequately in the community.

This approach promises to integrate the patient with his/her environment, and there is some evidence that the psycho-educational model aids in reducing rehospitalization rates and "improves community adjustment in chronic psychiatric patients in several aspects" (Agigian, Bencomo, and Hanson, 1973).

The overall picture of positive change in the status of the chronic mental patient using the psycho-educational model is good. Many instructional programs offered in day treatment centers (i.e. vocational training, personal hygiene, and stress management), appear to be important, but little evidence has been provided to show the effectiveness of a particular program content. The purpose of this study is to examine one of these themes, specifically stress management.

\section{Stress and Schizophrenia}

The relationship between schizophrenia and vulnerability to stress has been studied frequently by investigators over the past decade. These studies point to stress as an important factor in recidivism and psychotic episodes in schizophrenics (Beck and Worthen, 1972; Serban, 1975; Lin, Ensel, Simoene, Kuo, 1979; Brown, Harris, Peto, 
1973; Serban and Gidynski, 1979; Swartz and Myers, 1977; Mueller, Edwards and Yarvis, 1978).

George Serban (Serban, 1975, 1978, 1979, Serban and Gidynsky, 1979) has demonstrated a major difference in schizophrenics' reaction to life events compared to normal controls. In particular, a schizophrenic is more likely to experience stress because of his/her inability to function adequately in the environment. Additionally, Zubin and Spring (1977) noted the schizophrenics' heightened vulnerability to life events and the likelihood that a moderately stressful event for normals may be very stressful for schizophrenics.

This recognition, however, has not led to clinical research on secondary and tertiary prevention strategies. One reason may be the uncertainty over the viability of stress management training techniques which might prevent stress disorders or exacerbation of symptoms in schizophrenics.

\section{Stress Management Training}

A number of training programs in stress management has been shown to be effective in certain populations, specifically those suffering from anxiety and those with psychosomatic disorders (Benson, 1976). On the other hand, information concerning the effectiveness of stress 
management with schizophrenics, the population frequently involved in day treatment centers, is scarce.

One such study, (Bloom, Gonzalez, and Van Hassel,

1982 ) examined the effectiveness of two anxiety

interventions, Anxiety Management Training (AMT) and Applied Relaxation Training, on schizophrenic outpatients. Results of their study demonstrated reduced levels of anxiety in those treated contrasted with control subjects. Other behavioral improvements were reported also, indicating that stress management techniques may be useful in the treatment of schizophrenics. The results imply that schizophrenics can better manage stress in their lives if they are trained in stress management techniques. However, the question still remains: which techniques may be the most effective treatment approach? The particular stress management training program offered at the Portland, Oregon VA Hospital Day Treatment Center offered an opportunity to study the application of specific techniques in the amelioration of schizophrenia.

\section{DTC Training Format}

In conceptualizing the treatment of schizophrenia in this Portland VA stress management training program, the factors Serban identified as influencing the schizophrenic's unique stress reaction were considered. The schizophrenic individual appears to experience the world differently than 
the so-called normal individual. Given the reduced ability to organize their perceptions, people suffering from schizophrenia are likely to experience life events as more stressful than do others. This is closely aligned with the schizophrenic's difficulty in functioning adequately in his/her environment. Any stress management technique should address these two factors.

Within the structure of this intervention, certain assumptions were made concerning the treatment approach. The first assumption was that Behavioral Therapy would be most successful in this setting, and specifically that schizophrenics can learn skills which will improve their stress management ability. The second assumption was that it was important to address the subject's awareness of his/her behavior in the environment outside the treatment milieu. Thus, a stimulus-organism-response-consequence configuration for therapy was adopted. The environment and the individual's involvement in the current environment were the major points of focus for this particular class.

The structure of the class can be divided into two strategies. First, specific stress management techniques were explained in a didactic manner (See Appendix A), and practice on these techniques was encouraged and facilitated. Included in this strategy was an explanation of the relationship between stress and stressor, with an emphasis on individual reactions. This was the skills-training 
strategy. Second, a behavior graph was employed with the expectation that the subject would be able to track changes in feelings as correlated with changes in environment (See Appendix B). This was the behavior-graph strategy. Returning to the two factors influencing the schizophrenics' ability to manage stress as proposed by Serban, it can be seen how these interventions address those problems. The skills-training strategy would improve the individuals' ability to function in the community and the behavior-graph strategy would increase the individuals' ability to organize his/her perception of stressors in the environment. The first strategy, skills training, included instruction in relaxation training, recreation, exercise, and social network development. Relaxation training was included because research has demonstrated the value of reciprocal inhibition in the reduction of anxiety in subjects, (Wolpe, 1969, p. 15) and in the treatment of schizophrenics, (Alumbaugh, 1971; Slade, 1972). This technique, however, has not been shown to be a complete solution to the schizophrenic's difficulty with stress. One purpose of the present study was to test whether relaxation plus the other training might prove more effective than relaxation alone.

Relaxation training was the central aspect of the skills training strategy (Appendix A), but there was also training in other techniques which are commonly thought to 
reduce stress, either physiologically, as in exercise, or psychologically, as in recreation or social network development.

The second strategy, the behavior graph, was derived from behavior assessment and self-control methods. Essentially, the rationale for the behavior graph was to help the subject identify those environmental variables which may be influencing him/her emotionally and behaviorally. It was anticipated that alternative responses to environmental factors could be suggested as the individual gains insight into the relationship of environment and behavior, thereby relieving some of the perceived stress. When used in conjunction with skills training, it was thought the behavior graph would have an additive effect, and that it might improve the ability of the client to manage stress more than the skills training alone.

The dependent variables were drawn from the subject's internal impressions, and from behavior. Subjective factors included perceived stress and perceived functioning ability; both of these are discussed at length by Serban (1978). Additionally, symptoms of mental illness were assessed by a self-administered inventory, thereby tapping the internal operations of the subject. Observed anxiety was the objective evaluation for behavior. 
The experimental design was a simple $2 \times 2$ factorial, for all variables except for the behavior observations where repeated measures were taken. The factors were the skills training and the behavior graph. One group received both treatments, one group received only skills training, while one group received only the behavior-graph intervention. The control group received neither skills training nor behavior graph, (See Figure 1).

The null hypothesis is that there is no difference in the participant's ability to manage stress regardless of which treatment strategy is employed, and that there is no improvement in stress management for schizophrenics involved in these stress management strategies compared to schizophrenics receiving no training in stress management. 
Behavior Graph Instruction

Coping

Strategy

Instruction
Yes

No

\begin{tabular}{|c|c|}
\hline Yes & Group 1 \\
Manage-Chart & Manage \\
No & Group 4 \\
Group 2 & Control \\
\hline
\end{tabular}

Figure 1. Experimental Design. 


\section{METHOD}

\section{Setting}

The skills-training groups were conducted in a ward of the Vancouver VA Hospital. This ward was the location of the regular day treatment activities and consisted of two group rooms. The classes were taught in a large group room at Vancouver (Barnes) Hospital (See Appendix C) using visual aids such as posters and blackboard. Behavioral observations occurred in the Portland Mental Hygiene Clinic reception area, the Vancouver clubhouse room, and on the shuttle going to this classroom site from the Portland VA Mental Hygiene Clinic, (See Appendix C).

\section{Subjects}

The subjects for this study were 24 veterans with service-connected or non-service-connected psychiatric disabilities, many of whom recently were discharged from a VA psychiatric ward. They were previously selected by the staff of the Portland VA Day Treatment Center to participate in the therapeutic program. The selection criteria focused on the level of functioning in the environment and on the level of motivation for participating in day treatment classes. The required level of functioning was that the client be capable of supervised or autonomous living outside 
the hospital, and be able to take direction in a classroom setting. Subjects were also required to show enough motivation to present general goals for improvement in personal adjustment while participating in the program.

All DTC members attended several groups per week in the clinic setting, but otherwise had little association with the clinic or the VA Hospital. Most members met with their clinic case manager once a week to once a month for medication supervision, but this frequently was the limit of their involvement except during crisis.

When not attending day treatment they were either at their personal living quarters or they were performing other daily living activities outside of the clinic setting. Thus, these members were essentially unsupervised and functioned relatively independently when not attending DTC groups.

Since this is a veteran population, all clients were males between the ages of 25-60 years. All of the participants were taking antipsychotic medication at the time of the study, and every effort was made to stabilize medication during their participation in the program.

All of the participants were diagnosed as having schizophrenia, with the exception of two who were diagnosed as having bi-polar affective disorder. Although the latter clients were participants in the study, their results were excluded from consideration and analysis. For the purpose 
of this study, no distinction was made between the different types of schizophrenia. All participants had undergone frequent hospitalizations and their diagnoses were established by VA Hospital physicians using DSM III standards, (See Table I).

\section{Procedure}

Two weeks before the administration of the pre-tests each individual was provided with a consent form explaining the research and informing the participant of precautions we were taking to preserve their rights, and privileges. This form was designed to provide adequate information without compromising the results of the study, (See Appendix D). The content of the form made it clear that there were four different treatments within the study, and three of these related to coping with stress while one did not relate to coping with stress. Beyond this brief description there was no elaboration on the study itself.

One week prior to the administration of the pre-tests, volunteers from the day treatment population were selected for participation in the study. These volunteers were randomly assigned to the four experimental groups by having a volunteer withdraw from a box pieces of paper with the names of each subject printed on individual pieces of paper. The subjects were assigned to groups depending on the order in which they were drawn, the first name to the first group, 
TABLE I

CLINICAL INFORMATION BY SUBJECT

Gr Sub Age Diagnosis Type Anti-Psychotic
Medication

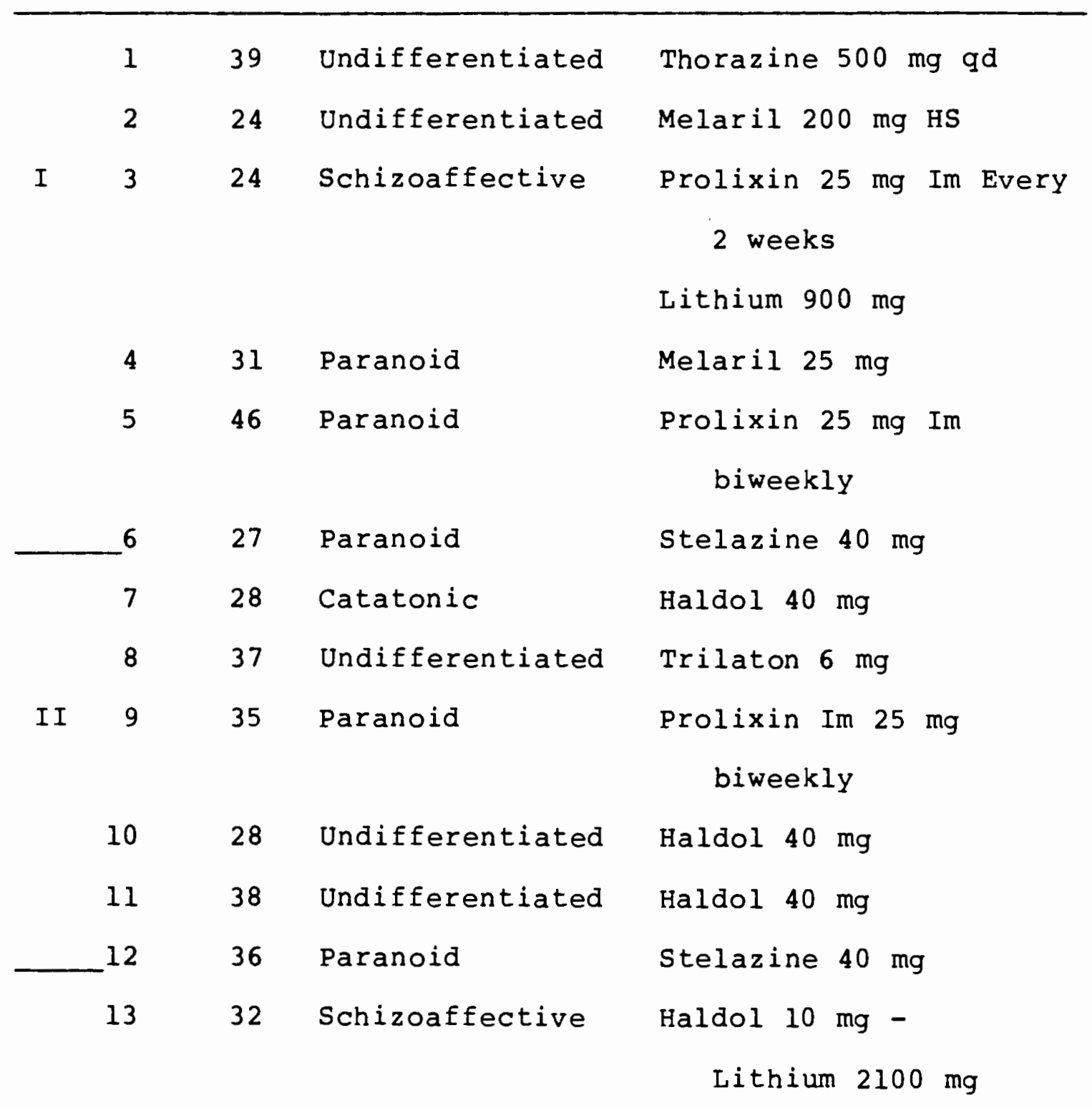




$\begin{array}{rr}\text { Gr Sub Age Diagnosis Type } & \text { Anti-Psychotic } \\ \text { Medication }\end{array}$

1433 Schizoaffective Prolixin $37.5 \mathrm{Im}$

biweekly

Lithium $300 \mathrm{mg}$

III 1525 Undifferentiated Haldol $40 \mathrm{mg}$

$16 \quad 35$ Paranoid Haldol $20 \mathrm{mg}$

1745 Undifferentiated Thorazine $150 \mathrm{mg}$

1841 Undifferentiated Trilaton $12 \mathrm{mg}$

1934 Schizoaffective Melaril $25 \mathrm{mg}$

20 27 Paranoid Stelazine $17 \mathrm{mg}$

IV $21 \quad 35$ Undifferentiated Prolixin $70 \mathrm{mg}$ Im

2235 Paranoid Stelazine $70 \mathrm{mg}$

2328 Paranoid Stelazine $10 \mathrm{mg}$

$24 \quad 24 \quad$ Paranoid Trilaton $6 \mathrm{mg}$ 
the second name to the second group, the third name to the third group, the fourth name to the fourth group, the fifth name to the first group, etc.

One week before the beginning of skills-training group each subject was administered a pre-treatment battery of two tests. The first test was the Social Stress and Functioning Inventory for Psychotic Disorders (SSFIPD) (Serban, 1978). The second was the Symptoms Check List (SCL-90), (Derogatis, 1973). The SSFIPD was administered by Day Treatment Centers case managers to each subject on an individual basis, asking the subject to respond to each question. The SCL-90 was self administered by each subject under the supervision of Day Treatment Center staff.

The SSFIPD is divided into two parts for the purpose of this research. The first section, composed of 174 items, is designed to cover various aspects of daily functioning and encompasses 21 dimensions of social role performance (Serban, 1978). Functioning was included to measure that aspect of adjustment which the psychiatrically impaired individual must have in order to live outside an institutional setting. Serban also notes that level of functioning seems to be related to the likelihood of readmission to the hospital, and that perceived stress seems to affect an individual's ability to function, (Serban, 1975). Thus the second section, composed of 130 items, is designed to assess the degree of experienced stress. 
The SCL-90 is a $90-i$ tem check 1 ist of symptoms commonly encountered in mental health settings. The participant rated each item on a five-point scale of problem severity. Four sets of scores can be derived: total number of problems; a total weighted score; symptoms cluster score (anxiety, anger, depression and obsessiveness) and factor scores (somatization, anxiety, neurotic feelings, performance difficulty and depression), (Derogatis, Lipman and Cori, 1973).

Both the SSFIPD (Serban, 1978) and the SCL-90 (Derogatis, 1973) have been standardized on appropriate populations and the SSFIPD is particularly appropriate for schizophrenics in the community (Serban, 1978).

Skills-training groups began on the first day of the week after the administration of the pre-test. During this week two trained observers (senior nursing students) rated each subject on behavior representing anxiety. Based on a scale by McReynolds (Maynard and McReynolds, 1962), ten items were rated on each participant using a five-point scale ranging from normal to extremely anxious. Staff members familiar with the study did not observe in order to avoid contamination of the results. Interrater reliability was checked at the beginning, middle and end of the study by comparing evaluations on the same subjects, (See Table II).

The first group was instructed in stress management and anxiety monitoring (See Appendix $A$ ). The subjects were 
TABLE II

INTERRATER RELIABILITY WITH

COHEN'S RAPPA COEFFICIENTS

\begin{tabular}{|c|c|c|c|c|c|c|c|}
\hline \multicolumn{8}{|c|}{ Observation } \\
\hline & Ia & Ib & $2 a$ & $2 b$ & $\star 2 c$ & $3 a$ & $3 b$ \\
\hline Kappa & 1.00 & .84 & .16 & .07 & .87 & .21 & .72 \\
\hline
\end{tabular}

* The coefficients at observations $2 a$ and $2 b$ indicated observer drift and necessitated further instruction and discussion. The coefficient of observation $2 c$ was obtained after instruction and discussion, which indicated improved agreement between observers. 
instructed in techniques for managing stress (e.g. relaxation, social network development, and exercise), and they were encouraged to practice these skills. Also, in this group the subjects were shown how to graph their experienced anxiety and mood on a chart, (See Appendix B) and asked to do so on a daily basis.

The second group was asked to graph the Anxiety-Mood chart on a daily basis and was instructed on the connection of anxiety and mood changes in response to stress, as was illustrated by the behavior graph. This group was not instructed on coping strategies. Daily charting was encouraged and fostered (See Appendix A).

The third group was given instruction on all of the coping strategies included in the combined group except the use of the Anxiety-Mood chart, (See Appendix A).

Despite efforts by the facilitator to encourage and foster the subjects' daily charting of subjective mood and anxiety on the graph, many of the subjects would skip a day or more, but no more than three days on charting. This problem was anticipated due to previous experiences with this population with regard to homework assignments. Follow-through seemed to be better on this assignment than in previous experiences, and no adjustment in experimental design was made to compensate for this deviation. 
The fourth group, designated as the control group, received no instruction on any of the strategies for managing stress.

All four groups continued as usual in other day treatment classes and functions, and were not deprived of usual treatment.

When they were not participating in the study, all of the subjects attended other groups, such as aerobic fitness, cooking and community groups. During the training periods offered by this study, the control group subjects did not participate in a formal group, but were allowed to socialize in a non-supervised setting. This non-participation was not unusual for this setting, because not all subjects were required to attend all groups during a specific hour.

All groups in this study met once weekly at a prearranged time. To eliminate the confounding effects of different trainers, each group was facilitated by the same staff member. Attendance was strongly encouraged and subjects who missed more than one group were not included in the results. Outlines of these groups are included in the appendix .

If any of the experimental strategies proved to be better than another at the end of the study, it was planned that all subjects would be given an opportunity to participate in that strategy at a later date. 
Finally, at the end of the eleven-week period, a battery of post-tests was administered to evaluate any possible change in the subjects. The SSFIPD was administered on the first and second day of the week following the last class. The SCL-90 was administered on the third day of the week following the last class. Behavioral observations continued during this week, but were completed on the third day following the last class, during other Day Treatment activities. 


\section{RESULTS}

For evaluation of the results of the research, Factorial Analysis of Covariance was used. To analyze the repeated behavioral observations on the group, a repeated-measures version of ANCOVA was used. An alpha level of .05 was used in all tests for significance. In all of the measures of change, the first observation was designated as the covariate. All subsequent measures were evaluated as dependent variables.

The analysis of covariance was used to statistically control for the likelihood that the groups would differ considerably in the pre-test measure. This assumption was made despite the attempt to control the group differences by random assignment of subjects. The reason for this assumption was that the small number of subjects might allow large differences among groups despite random assignment of subjects.

For brevity's sake, the independent variables will be referred to as Manage, for teaching stress management techniques; Chart, for having the subject track mood and anxiety over time; and Manage-Chart, for the combination of these strategies. 
None of the groups was significantly different from the others at the .05 level of confidence. In the symptom Check List-90 (SCL-90) three scales were considered; the Global Severity Index (GSI), the psychotic scale, and the anxiety scale. As noted above none of the groups was significantly different, (See Tables III, IV, V). The only group approaching significance on any SCL-90 scale was the Manage group on the psychotic scale, and it only achieved a .08 probability level with $F=3.39$, (See Table IV). The baseline score on all three scales was significant, however. These scores represent the correlation between the individual pre and post-test scores. The baseline significance shown on the tables suggests a strong test-retest correlation. This implies that the measure was reliable over the period of the study. It also implies that the intervention was not successful in changing the individual scores. In other words, the greater the treatment effect, the less correlation one would expect between individual pre and post-test scores.

similar results were obtained on analysis of covariance on the Social stress and Functioning Inventory for Psychotic Disorders (SSFIPD). The two scales functioning and stress showed no significance at the .05 level of confidence, with the exception of the correlation of baseline and post-test results, as reflected by the 
TABLE III

ANALYSIS OF COVARIANCE FOR GLOBAL SEVERITY INDEX SCALE SCORES (SCL-90)

\begin{tabular}{lrcccc}
\hline Source & $\begin{array}{c}\text { Sum of } \\
\text { Squares }\end{array}$ & $\begin{array}{c}\text { Degrees of } \\
\text { Freedom }\end{array}$ & $\begin{array}{c}\text { Mean } \\
\text { Square }\end{array}$ & F & Tail \\
& & & & & Prob. \\
\hline Manage & 56.34276 & 1 & 56.34276 & 1.25 & 0.2784 \\
Chart & 16.72619 & 1 & 16.72619 & 0.37 & 0.5504 \\
MC & 0.13665 & 1 & 0.13665 & 0.00 & 0.9568 \\
Base GSI & 2077.23202 & 1 & 2077.23202 & 45.90 & 0.0000 \\
Error & 859.76798 & 19 & 45.25095 & & \\
\hline
\end{tabular}


TABLE IV

ANALYSIS OF COVARAINCE FOR

PSYCHOTIC SCORES (SCL-90)

\begin{tabular}{lccccc}
\hline Source & Sum of & Degrees of & Mean & F & Tail \\
& Squares & Freedom & Square & & Prob. \\
& & & & & \\
Manage & 333.21440 & 1 & 333.21440 & 3.39 & 0.0813 \\
Chart & 68.71879 & 1 & 68.71879 & 0.70 & 0.4135 \\
MC & 14.51712 & 1 & 14.51712 & 0.15 & 0.7051 \\
Base Psy & 3802.81125 & 1 & 3802.81125 & 38.68 & 0.0000 \\
Error & 1868.18875 & 19 & 98.32572 & &
\end{tabular}


TABLE V

ANALYSIS OF COVARAINCE FOR

ANXIETY SCORES (SCL-90)

\begin{tabular}{lrrrrr}
\hline Source & $\begin{array}{c}\text { Sum of } \\
\text { Squares }\end{array}$ & $\begin{array}{c}\text { Degrees of } \\
\text { Freedom }\end{array}$ & $\begin{array}{c}\text { Mean } \\
\text { Square }\end{array}$ & F & $\begin{array}{l}\text { Tail } \\
\text { Prob. }\end{array}$ \\
\hline Manage & 0.66667 & 1 & 0.66667 & 0.00 & 0.9567 \\
Chart & 2.66137 & 1 & 2.66137 & 0.01 & 0.9136 \\
MC & 245.19660 & 1 & 245.19660 & 1.11 & 0.3045 \\
Base Anx & 1253.77232 & 1 & 1253.77232 & 5.69 & 0.0276 \\
Error & 4183.22768 & 19 & 220.16988 & & \\
\hline
\end{tabular}


base functioning and base stress analyses, (See Tables VI and VII).

The Analysis of Covariance with Repeated Measures on the behavioral observations showed the same lack of significance at the .05 level of confidence, (See Table VIII).

The only difference in this analysis and the previous analyses of the SCL-90 and SSFIPD was the lack of significance in the Base Observation correlation with the post-test scores of individuals. The tail probability was .1057 , above the .05 level of confidence. This result would suggest the possibility of reduced test-retest reliability over the period of the study. This evidence supports the observer drift suggested by Cohen's kappa coefficients in Table II. Overall, these results may underlie some difficulty in the observer training on the test-retest problem in the observation tool, since there were no significant differences among the groups.

The cell means, standard deviations and adjusted cell means of all outcome measures are listed in Tables IXa, $I X b, I X c, X a, X b, X I a$, and XIb. 
TABLE VI

ANALYSIS OF COVARIANCE OF STRESS SCORES (SSFIPD)

\begin{tabular}{lccccc}
\hline Source & $\begin{array}{c}\text { Sum of } \\
\text { Squares }\end{array}$ & $\begin{array}{c}\text { Degrees of } \\
\text { Freedom }\end{array}$ & $\begin{array}{c}\text { Mean } \\
\text { Square }\end{array}$ & F & $\begin{array}{c}\text { Tail } \\
\text { Prob. }\end{array}$ \\
\hline Manage & 0.71665 & 1 & 0.71665 & 0.04 & 0.8536 \\
Chart & 2.20594 & 1 & 2.20594 & 0.11 & 0.7463 \\
MC & 50.6796 & 1 & 50.6796 & 2.48 & 0.1321 \\
Base Strs & 391.37339 & 1 & 391.37339 & 19.12 & 0.0003 \\
Error & 388.97516 & 19 & 20.47238 & & \\
\hline
\end{tabular}


TABLE VII

ANALYSIS OF COVARIANCE FOR

FUNCTION SCORES (SSFIPD)

\begin{tabular}{lccccc}
\hline Source & $\begin{array}{c}\text { Sum of } \\
\text { Squares }\end{array}$ & $\begin{array}{c}\text { Degrees of } \\
\text { Freedom }\end{array}$ & $\begin{array}{c}\text { Mean } \\
\text { Square }\end{array}$ & F & $\begin{array}{c}\text { Tail } \\
\text { Prob. }\end{array}$ \\
\hline Manage & 1.98035 & 1 & 1.98035 & 0.14 & 0.7128 \\
Chart & 0.65416 & 1 & 0.65416 & 0.05 & 0.8322 \\
MC & 39.91448 & 1 & 39.91448 & 2.81 & 0.1098 \\
Base Func & 344.55370 & 1 & 344.55370 & 24.30 & 0.0001 \\
Error & 269.44555 & 19 & 14.18134 & &
\end{tabular}


TABLE VIII

ANALYSIS OF COVARIANCE WITH REPEATED

MEASURES FOR BEHAVIORAL OBSERVATIONS

\begin{tabular}{lccccc}
\hline Source & $\begin{array}{c}\text { Sum of } \\
\text { Squares }\end{array}$ & $\begin{array}{c}\text { Degrees of } \\
\text { Freedom }\end{array}$ & Mean & Square & \\
& & & & Tail \\
Manage & 0.19657 & 1 & 0.19657 & 0.57 & 0.4586 \\
Chart & 0.41000 & 1 & 0.41000 & 1.19 & 0.2883 \\
MC & 0.79328 & 1 & 0.79328 & 2.31 & 0.1451 \\
Base obs & 0.99139 & 1 & 0.99139 & 2.89 & 0.1057 \\
Error & 6.52638 & 19 & 0.34349 & & \\
\hline
\end{tabular}


TABLE IXa

SCL-90 GLOBAL SEVERITY INDEX MEANS

AND STANDARD DEVIATIONS

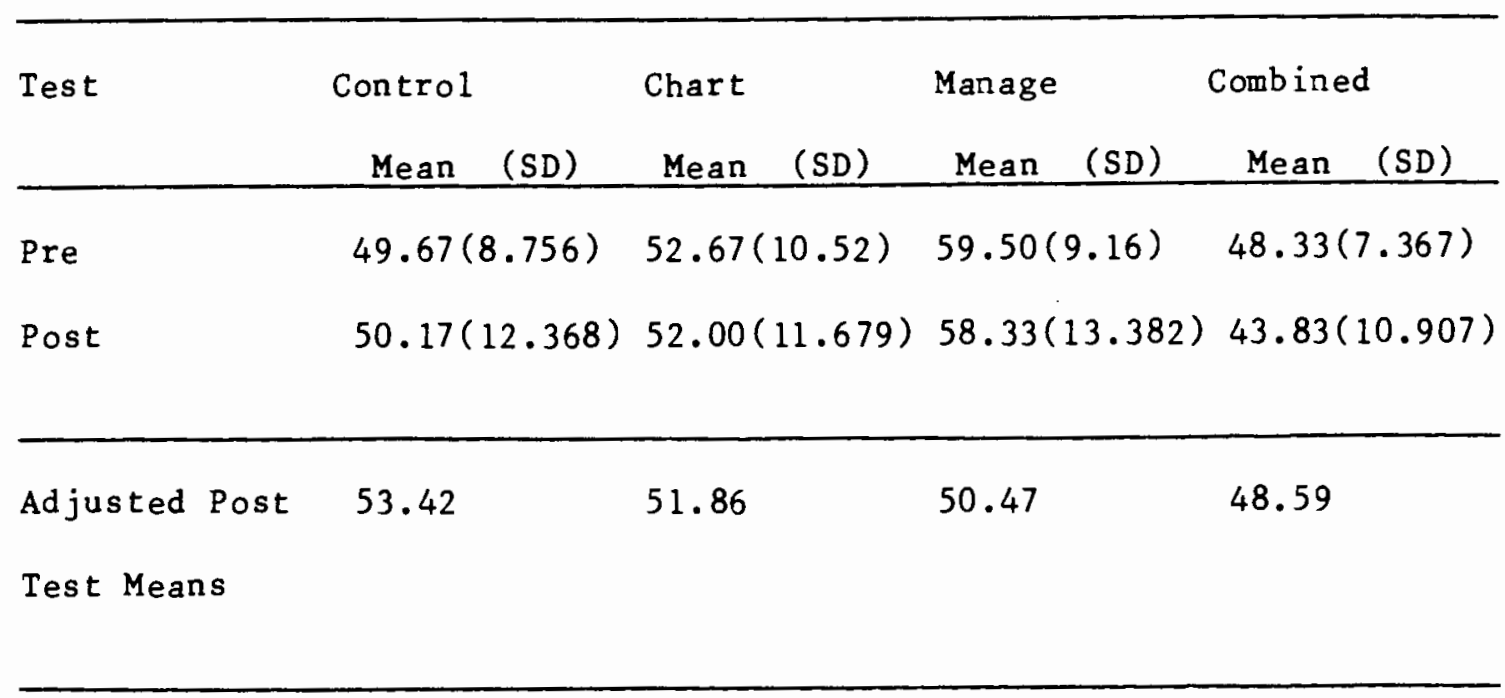

TABLE IXb

SCL-90 PSYCHOTIC SCALE MEANS

AND STANDARD DEVIATIONS

\begin{tabular}{|c|c|c|c|c|}
\hline \multirow[t]{2}{*}{ Test } & Control & Chart & \multirow{2}{*}{$\begin{array}{c}\text { Manage } \\
\text { Mean } \\
\end{array}$} & Combined \\
\hline & Mean & Mean & & Mean \\
\hline Pre & $53.33(7.118)$ & $53.83(11.409)$ & $60.33(11.742)$ & $53.83(9.704)$ \\
\hline Post & $54.33(15.08)$ & $53.17(12.86)$ & $57.83(14.662)$ & $44.00(22.943)$ \\
\hline Ad justed & 57.05 & 55.20 & 51.05 & 46.04 \\
\hline Post Test & & & & \\
\hline
\end{tabular}


TABLE IXC

SCL-90 CELL MEANS AND STANDARD

DEVIATIONS FOR ANXIETY SCALE

\begin{tabular}{|c|c|c|c|c|}
\hline \multirow[t]{2}{*}{ Test } & Control & Chart & Manage & Combined \\
\hline & Mean & Mean & Mean & Mean \\
\hline Pre & $49.33(7.448)$ & $53.33(9.136)$ & $56.00(5.762)$ & $56.67(7.209)$ \\
\hline Post & $41.50(21.324)$ & $52.17(11.583)$ & $53.33(9.026)$ & $37.67(20.422)$ \\
\hline Ad justed & 43.62 & 50.05 & 50.40 & 42.60 \\
\hline Cell Means & & & & \\
\hline
\end{tabular}


TABLE Xa

MEANS AND STANDARD DEVIATIONS FOR FUNCTION SCALE

ON SOCIAL STRESS AND FUNCTIONING INVENTORY

FOR PSYCHOTIC DISORDERS (SSFIPD)

\begin{tabular}{|c|c|c|c|c|}
\hline Test & Control & Chart & Manage & Combined \\
\hline & Mean (SD) & Mean & Mean & Mean \\
\hline Pre & $37.673(4.295)$ & $35.885(4.647)$ & $35.617(9.492)$ & $36.7 \quad(4.355)$ \\
\hline Post & $37.462(3.794)$ & $33.315(5.428)$ & $34.038(8.413)$ & $37.045(2.859)$ \\
\hline Adjusted Cell & 36.643 & 33.712 & 34.618 & 36.888 \\
\hline Mean Post Test & & & & \\
\hline
\end{tabular}

TABLE Xb

MEANS AND STANDARD DEVIATIONS FOR STRESS SCALE SSFIPD

\begin{tabular}{|c|c|c|c|c|}
\hline \multirow[t]{2}{*}{ Test } & Control & Chart & Manage & Combined \\
\hline & Mean & Mean & Mean (SD) & Mean \\
\hline Pre & $34.325(3.239)$ & $34.01(3.307)$ & $29.91(8.55)$ & $34.937(3.074)$ \\
\hline Post & $33.913(5.423)$ & $36.038(3.528)$ & $33.455(9.243)$ & $34.170(5.364)$ \\
\hline Adjusted Cell & 33.01924 & 35.41746 & 36.39458 & 32.74538 \\
\hline Mean Post Test & & & & \\
\hline
\end{tabular}


TABLE XIa

MEANS AND STANDARD DEVIATIONS FOR BEHAVIORAL OBSERVATIONS; BASELINE PLUS THREE OBSERVATIONS OCCURRING THREE WEEKS APART

\begin{tabular}{llllllllll}
\hline Observation & Control & & Chart & & Manage & \multicolumn{3}{c}{ Combined } \\
& Mean & (SD) & Mean & (SD) & Mean & (SD) Mean & (SD) \\
\hline Base & 1.9333 & $(.3615)$ & 2.617 & $(.4834)$ & 2.35 & $(.7688)$ & 2.28 & $(.3971)$ \\
First & 1.883 & $(.407$ & 2.217 & $(.6524)$ & 2.133 & $(.5645)$ & 1.85 & $(.4037)$ \\
Second & 2.1 & $(.9879)$ & 2.25 & $(.1643)$ & 2.25 & $(.5431)$ & 1.817 & $(.3545)$ \\
Third & 1.83 & $(.2251)$ & 2.05 & $(.2588)$ & 2.1 & $(.5514)$ & 1.617 & $(.2639)$ \\
& & & & & & & & & \\
\hline
\end{tabular}

TABLE XIb

ADJUSTED CELL MEANS FOR BEHAVIORAL OBSERVATIONS

\begin{tabular}{lcccc}
\hline Observation & Control & Chart & Manage & Combined \\
\hline Base & 1.933 & 2.617 & 2.35 & 2.28 \\
First & 1.987 & 2.125 & 2.118 & 1.854 \\
Second & 2.139 & 2.216 & 2.244 & 1.818 \\
Third & 1.956 & 1.94 & 2.082 & 1.621 \\
\hline
\end{tabular}




\section{DISCUSSION}

The results of this study apparently do not support anything except the null hypothesis. Analysis shows no significant differences among the various interventions in their impact on anxiety as represented by behavior observation scores, functioning and perceived stress as rated by the SSFIPD, or anxiety, psychotic and overall symptom scales as rated on the SCL-90. The statistical analysis, however, does not completely show certain trends in the results which appear when the means are graphed.

The graphing of mean scores of the groups on outcome measures suggests trends and patterns and a possibility of differences in the various strategies not identified by the statistical analysis. In the behavioral observations, for example, the combined strategies of manage and chart show an observable scale drop of .66 , compared to the control group of .5I (See Figure 4). We know that this is not significant beyond chance, but it does raise one's curiosity. If we look further, the combined strategy is the only one that showed an improvement on functioning (SSFIPD), albeit small and insignificant, (See Figure $3 a$ ).

If we look at the slope of the SCL-90 (Figure $2 a, 2 b$, and $2 c$ ) on the Global Severity Index, it can be seen that 


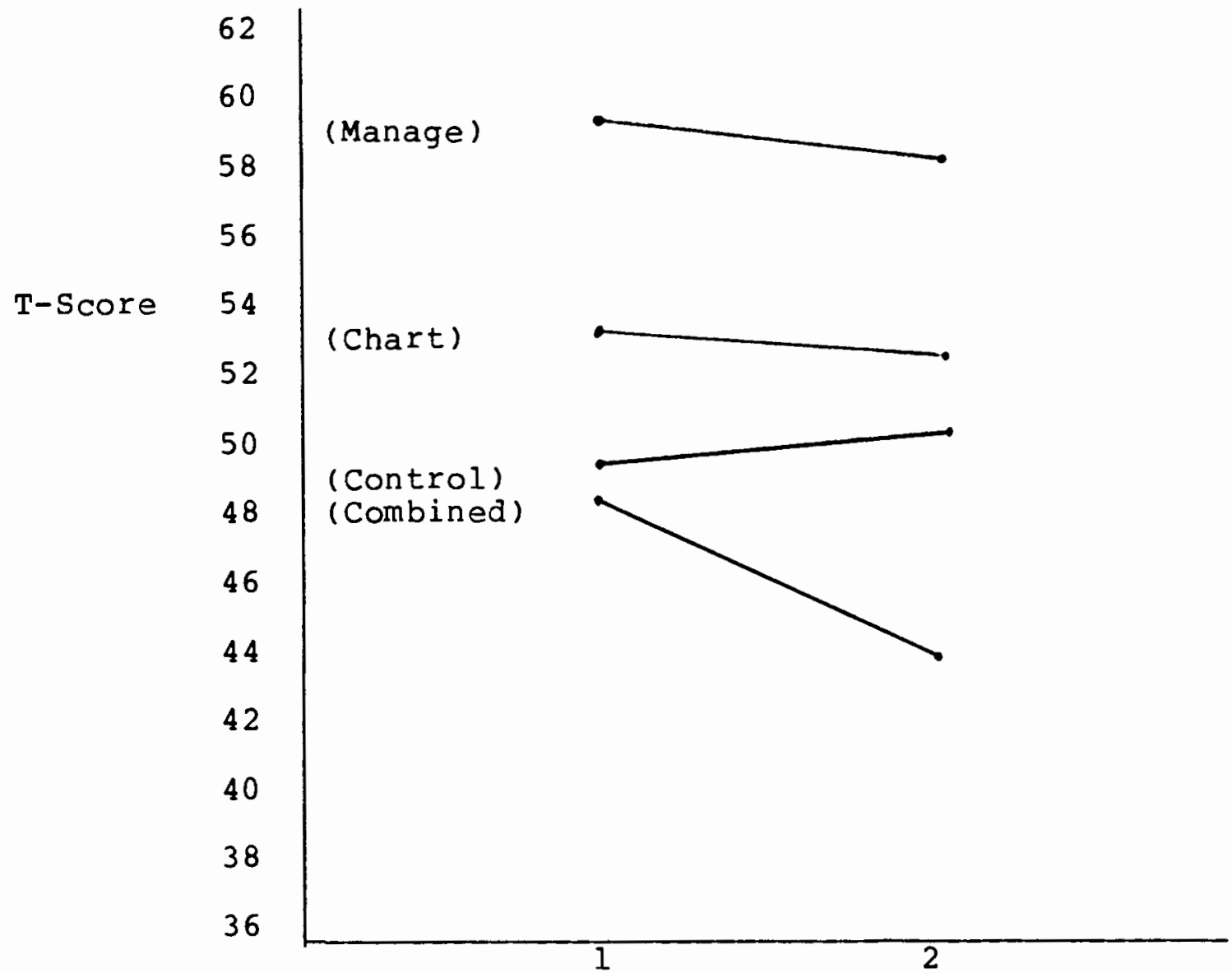

Figure 2a. SCL-90 Means on Global Security Index. 


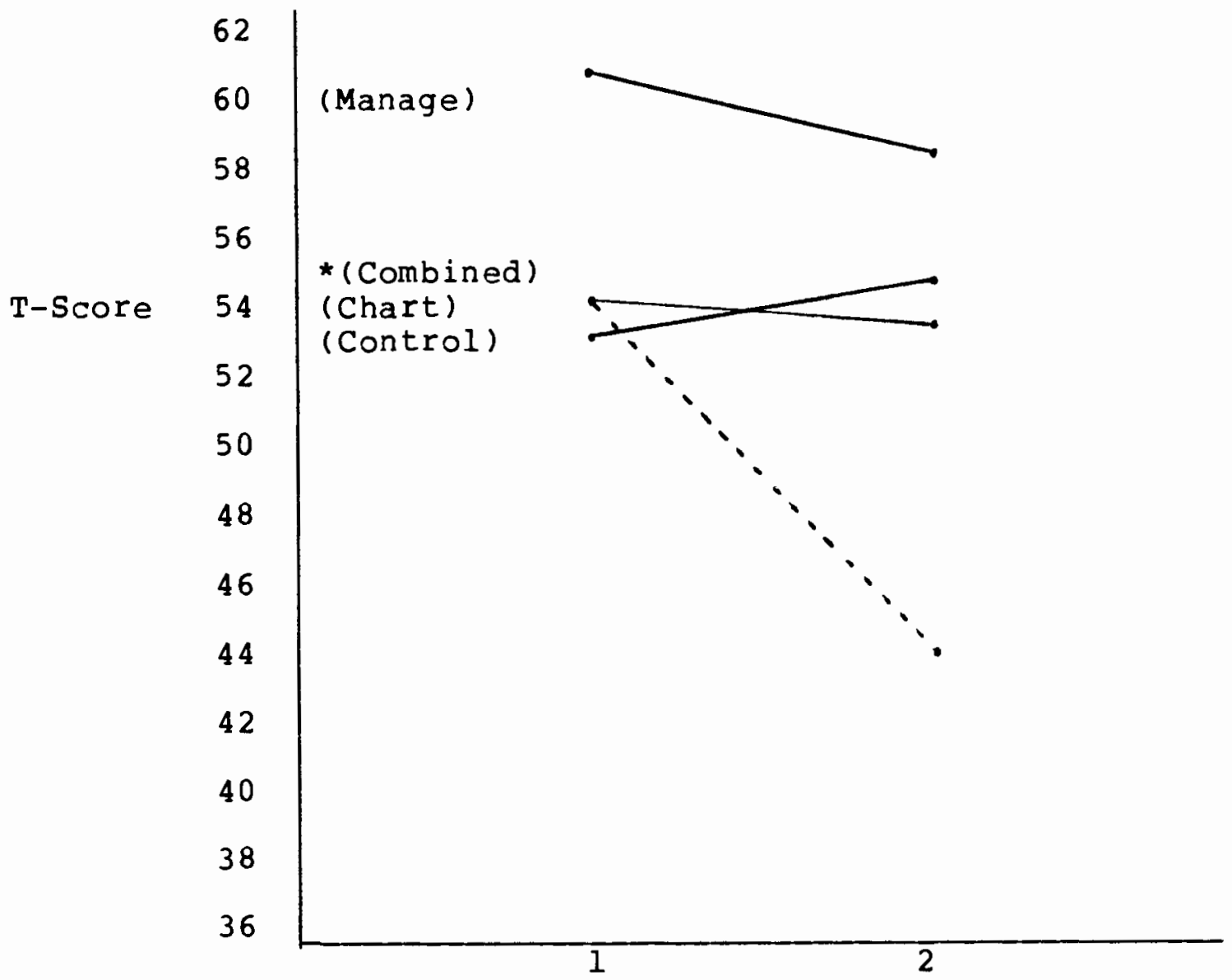

Test Sequence

* Because the pretest combined score is identical with the chart score the combined slope will be delineated with a dotted line.

Figure 2b. SCL-90 Means on Psychotic Scale. 


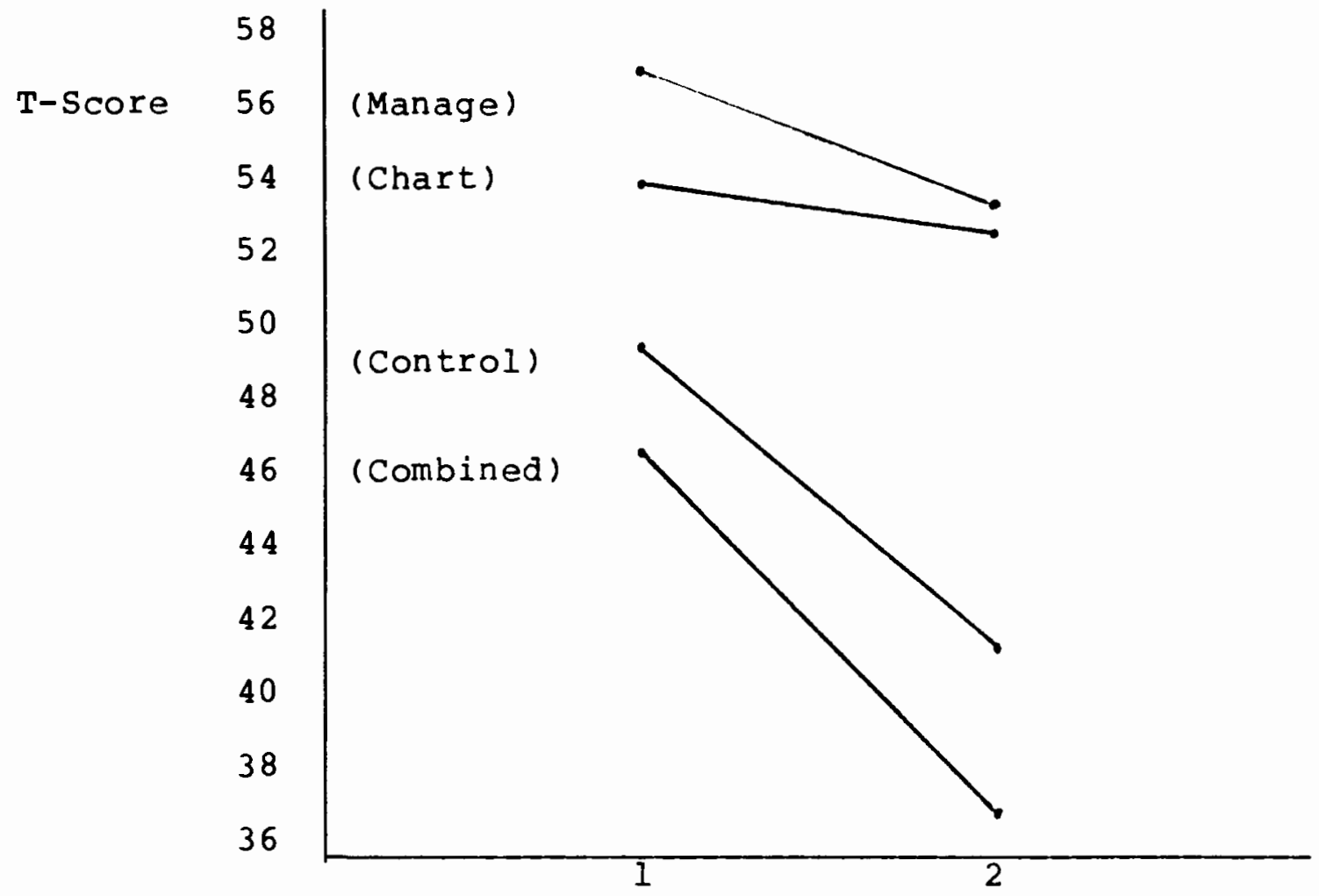

Test Sequence

Figure 2c. SCL-90 Means on Anxiety Scale. 


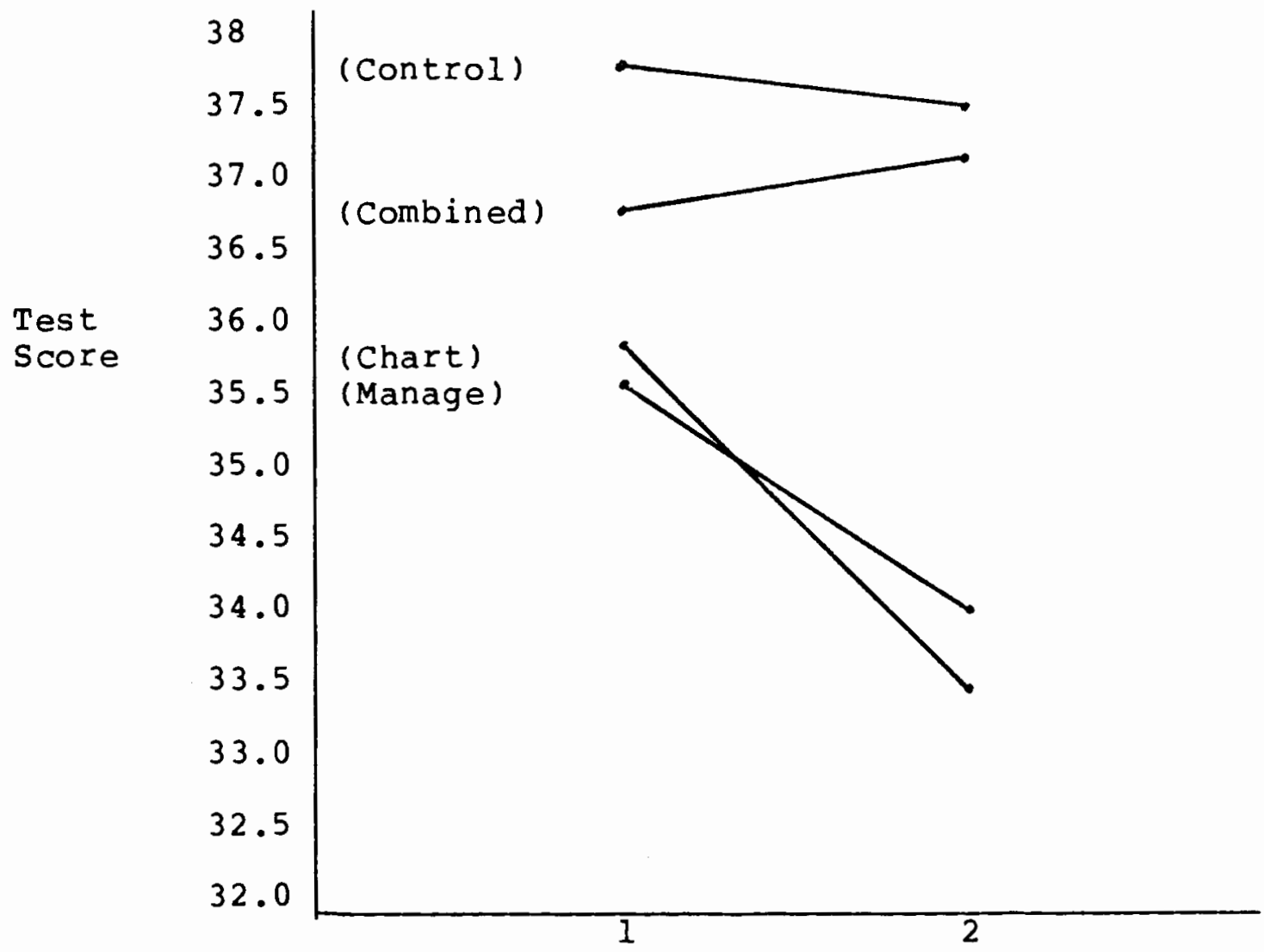

Test Sequence

Figure 3a.. SSFIPD Means for Function Scale. 


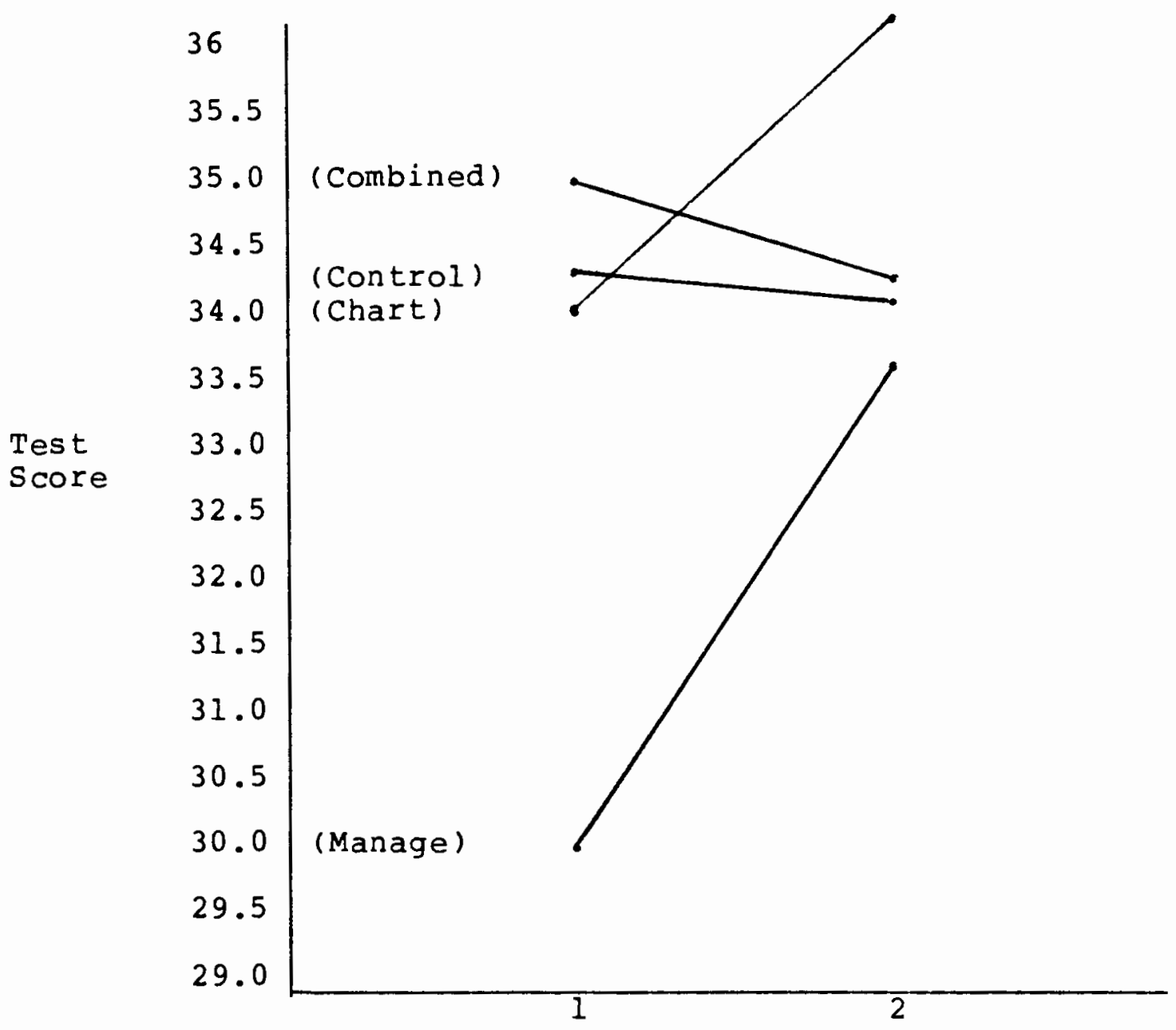

Test Sequence

Figure 3b. SSFIPD Means for Stress Scale. 


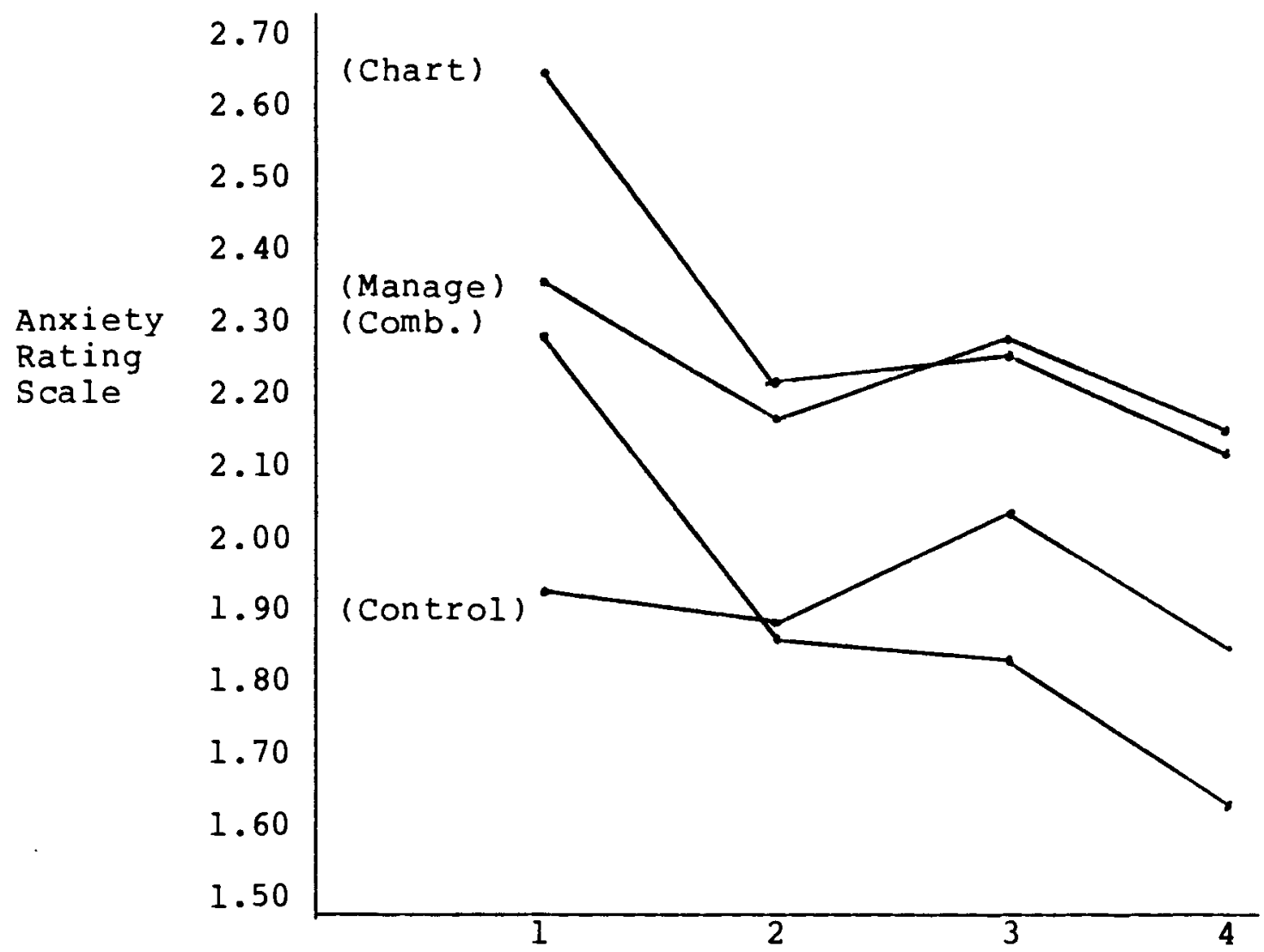

Observations

(Each approximately three weeks apart)

Figure 4. Means for Behavioral Observations Sequentially Represented. 
the combined group does diverge from the slope patterns of the other interventions. This pattern appears to be repeated in the psychotic scale, although the Manage slope drops in a similar direction in all cases.

This would hint that the combination of the management and chart technique could bear further research. This may be especially true in consideration of the sample size of 24 subjects. This sample size may lead to accepting the null hypothesis when indeed there may be some differences in the efficacy of the various strategies.

Another problem associated with this study is the difficulty of separating the stress management techniques from the milieu of the Day Treatment Center (DTC) itself. The control group, as well as all treatment groups received the treatment provided by the DTC. Much of this program also addresses the stress management needs of the chronic mentally ill. For example, there is an exercise class, goals groups and a social network development class, in addition to the therapeutic atmosphere of program facility. Given the therapeutic gain developed by the DTC, further improvement from the experimental treatments might be limited. If the control group were drawn from a less structured setting, the results might be different. However, this would not aid in the determination of what is most effective in the day treatment style of programing. 
Both of the criticisms above suggest that increasing the sample size might improve the possibility of finding significant results. However, there were no significant findings. We may assume from these results that the stress management strategies did not improve the subjects ability to function over the improvement from the DTC program as a whole. This does not lead us irrevocably to the conclusion that these stress management techniques would be useless in a different setting or that they may be helpful in this. It only demonstrates that there is no evidence to support their use as teaching techniques over and above the DTC programming in general.

A third problem with this study is that the lack of significance contrasts with the significance shown by Bloom, Gonzolez and Van Hassel (1982) in their study of stress management with schizophrenics. The Bloom, et. al., study showed a significant reduction on the generalized anxiety continuim as measured by the Speilburger Trait Anxiety Inventory (STAI) in the Anxiety Management Training (AMT) group compared with the control group. The obvious question is: What is the difference between these research effects? The major difference between these studies is the 45-minute, six-week Anxiety Management Training session emphasizing relaxation training and a specialized desenzitization technique. Whereas, the present study focuses more on the psychoeducational presentation of several stress management 
strategies, including relaxation, social network development, exercise, and leisure planning.

It is reasonable to expect that the above mentioned difference would impact the variation of effect in the results of the two studies. Intense focus on a single stress management strategy may well have more influence than brief education on a variety of strategies. Other differences in the studies might also impact the significance of results. The AMT group was twice the size (six versus 14) of the group sample size in the present study. Also, the AMT study sample was drawn from the outpatient clinic in general, and did not have the background of the milieu to reduce the contrast of treatment effect.

Differences between the two studies suggest some changes in possible future investigation of effective stress management techniques for schizophrenics. These changes are as follows: (1) the sample size could be increased, (2) the sample could be drawn from a clinic outside the Day Treatment Center and other intense milieu programs, (3) each group could be focused on one specific intervention, e.g. relaxation or, (4) the number of training sessions could be increased to allow for additional training.

In conclusion, this research does not support the continuation of this particular stress management training in the DTC. It does, however, beg the question of a 
different research design, or suggests the possibility of increasing the sample size through replication of the study. Given the across-the-board lack of significant findings we might be inclined to dismiss the efficacy of this stress management approach to schizophrenia, but the graphic representation of the results raise some interesting questions. Thus, the prudent course may be to reevaluate the study itself as suggested above, and continue the search for interventions effective in relieving the subjective experience of stress in schizophrenics. 
REFERENCES

Agigian, H., Bencomo, A., \& Hanson, R. (1973).

Rehabilitating Chronic Psychiatric Patients in a Day Treatment Center: An Educational-Behavioral-Social Systems Approach: unpublished, Palo Alto, VA Hospital, Palo Alto, California.

Alumbaugh, R.V. (1971). Use of behavior modification techniques toward reduction of hallucinatory behavior: A case study. Psychological Record, 21, 415-417. Beck, J.C. \& Worthen, K. (1972). Precipitating Stress, Crisis Theory, and Hospitalization in Schizophrenia and Depression. Archives of General Psychiatry, 26, $123-129$.

Benson, H. (1976). The Relaxation Response, Avon Books, The Hearst Corporation, New York, New York. Bloom, L., Gonzalez, A., \& Van Hassel, J. (1982). Anxiety Management with Schizophrenic Outpatients. Journal of Clinical Psychology, $\underline{3}$ (2), (April), $280-285$.

Brown, G.W., Harris, T.O., \& Peto, J. (1973). Life Events and Psychiatric Disorders. Part 2. Nature of Causal Link. Psychological Medicine, $\underline{3}, 159-179$. Derogatis, L.R. (1975). The SCL-90-R Clinical Psychometrics Research, Baltimore. 
Derogatis, L.R., Lipman, R.S., \& Covi, L. (1973). SCL-90: An Outpatient Psychiatric Rating Scale - Preliminary Report. Psychopharmacology Bulletin: $\underline{9}$ (1), 15-27. Lin, N., Ensel, W.M., Kuo, W., \& Simeone, R.S. (1979). Social Support, Stressful Life Events, and Illness: A Model and an Emperical Test. Journal of Health and Social Behavior, 20 (June) 108-119.

Maynard, H. \& McReynolds, P. (1962). A Longitudinal

Comparison of Four Measures of Anxiety, Research Reports of VA Palo Alto No. 23, December, unpublished. Mueller, D.P., Edwards, D.W. \& Yarvis, R.M. (1978).

Stressful Life Events and Community Mental Health Center Patients. The Journal of Nervous and Mental Disease, 166 (1) $16-24$.

Paul, G.L. (1966). Insight vs. Desensitization in

Psychotherapy. Stanford: Stanford University Press. Schwartz, C., \& Myers, J. (1977). Life Events and Schizophrenia. Archives of General Psychiatry, 34 (October), 1238-1241.

Serban, G. (1975). Relationship of Mental Status, Functioning and Stress to Readmission of Schizophrenics. British Journal Clinic Psychology, 14, 291-301. Serban, G. (1975). Stress in Schizophrenics and Normals. British Journal of Psychiatry, 126, 397-407.

Serban, G. (1978). Social Stress and Functioning Inventory for Psychotic Disorders (SSFIPD): Measurement and 
Prediction of Schizophrenics' Community Adjustment. Comprehensive Psychiatry, July/August, 19, 4 . Serban, G. (1979). Mental Status, Functioning, and Stress in Chronic Schizophrenic Patients in Community Care. American Journal of Psychiatry, July, 136, 7. Serban, G., \& Gidynski, C.B. (1979). Relationship Between Cognitive Defect, Affect Response and Community Adjustment in Chronic Schizophrenics. British Journal, $134,602-8$

Slade, P.D. (1972). The effects of systematic desensitization on auditory hallucinations. Behavior Research and Therapy, 10, 85-91. Wolpe, J. (1958). Psychotherapy by Reciprocal Inhibition. stanford, Calif., Stanford University Press. Wolpe, J. (1969). The Practice of Behavior Therapy. New York, Pergamon Press. Zubin, J., \& Spring, B. (1977). Vulnerability - A New View of Schizophrenia. Journal of Abnormal Psychology, 86 (2), 103-126. 


\section{APPENDIX A \\ GROUP DESCRIPTIONS AND OUTLINES \\ Group I / Combined Strategy}

In this group, instruction is divided between coping strategies for managing stress and the use of the Anxiety-Mood Chart. Instruction was given verbally and was written on the blackboard. Initial guidelines for the proper use of the chart was identical for this group and group two, which is designed for chart instruction only. (See Appendix B).

Class I Introduction (See Appendix B).

Class 2 Have participants present chart and discuss20 minutes. Present relaxation. Practice Goldfried technique for muscle tensing and relaxing exercises. (Copyright 1976 , BioMonitoring applications, Inc.) 40 minutes.

Class 3 Present and discuss chart-20 minutes. Continue relaxation with breathing for conditioned relaxation using cue word such as "calm" for relaxation response in stressful role play (Paul, 1966). 40 minutes.

Class 4 Present and discuss chart-20 minutes. Present social support system. Role play asking for help from friend. 40 minutes. 
Class 5 Present and discuss chart. 20 minutes. present exercise as strategy for improving depression. Participants prepare week of exercises. 40 minutes.

Class 6 Present and discuss chart. 20 minutes. Do stressful situation role play (situation decided by participant) and use one coping strategy to manage stress. 40 minutes.

Class $7 \& 8$ Same as 6 .

Class 9 Present and discuss chart. 20 minutes. Present prevention of stress strategies. (See Appendix B). 40 minutes.

Group $2 /$ Anxiety-Mood Chart

Class 1 Introduction (See Appendix B).

Class 2 present and discuss chart. (20 minutes). Open ended discussion*, or socialization. $\quad(40$ minutes).

Classes 3 through 9 are same as above.

* Discussion will avoid instruction on charts, or conversation about chart content. 
Group 3 / Coping Strategies Class

Class 1 Introduction (Appendix B).

Class 2 Role play stressful situation and discuss coping strategies. (40 minutes). Open-ended discussion* group. (20 minutes).

Class 3 present relaxation. practice relaxation and tensing of muscles as in the Goldfried technique (Copyright 1976, BioMonitoring Applications, Inc.). 40 minutes. Discussion 20 minutes.

Class 4 Continue relaxation. Practice breathing for conditioned relaxation, using a cue word such as "calm" for relaxation response in stressful situation. (Paul, 1966). 40 minutes. Discussion 20 minutes.

Class 5 Present social support system developing. Role play asking someone for help or to talk about problem. 40 minutes. Discussion 20 minutes.

Class 6 Present exercise as helpful activity in improving depression. Participants prepare weekly program. 40 minutes. Discussion 20 minutes.

Class 7 Role play stressful situation (decided by client) and use strategies presented above to manage stress. 40 minutes. Discussion 20 minutes. 
Class 8 Role play as above. 40 minutes. Discussion 20 minutes.

Class 9 Prevention of stress presentation and discussion (See Appendix B). Open discussion. 20 minutes.

* Open discussion will not be instructive and will avoid elaboration on coping strategies. 
APPENDIX B

INSTRUCTION MATERIAL

\section{Introduction}

1) Description of class, depending upon group.

2) Define terms (e.g. stress and stressor).

3) Describe relationship of environment and anxiety.

4) Introduce concept of coping strategies in groups one and three.

5) Encourage a sense of ability to manage stress.

6) Introduce idea of Anxiety-Mood Chart. Read initial guidelines and provide time for subjects to fill out under supervision.

\section{Chart Instructions}

You are now looking at the Anxiety-Mood Chart. You are asked to fill this chart out on a daily basis, keeping track of your anxiety and your mood. You will do this by placing a dot on the line under one of the time indicators at the position that describes your feeling at that time. In other words, at 4 p.m. you may have little anxiety so you would mark across from "good" on the chart under 4 p.m. for that day.

I would like to remind you that it is important to keep your charts updated frequently. It is often difficult to remember what was happening a few hours ago, and even 
more difficult to remember your feelings the day before. So take this opportunity to complete your chart, and please attempt to keep your chart accurate throughout the week. If you are uncertain of how to fill out the chart, please ask for help. 
Stress Management Guide Lines

1) Have some meaningful activity that you like - volunteer work and/or recreation.

2) Avoid getting over extended. Watch for stressful events when they get too frequent or "pile up".

3) Understand yourself how stress effects you and what are stressors in your life. Learn to recognize when you are under stress.

4) Have some exercise each and every day, if possible a regular routine of strenous exercise and use it when under stress.

5) Learn relaxation techniques: 1. Breathing

2. Tensing and Relaxing Muscles

6) Develop a social support network - have friends and professionals help in crises.

7) Manage your life habits to avoid increasing stress

- maintain hygiene

- watch budget

- maintain proper medication

- avoid street drugs - this includes alcohol and mari juana.

8) When you anticipate stress, talk to therapist about anxiety. 


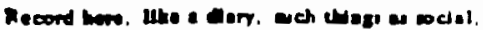

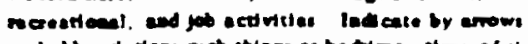

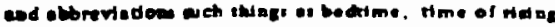

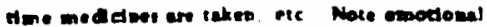

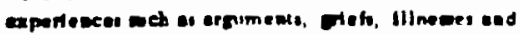

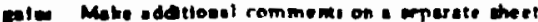
II $x \cos 4$
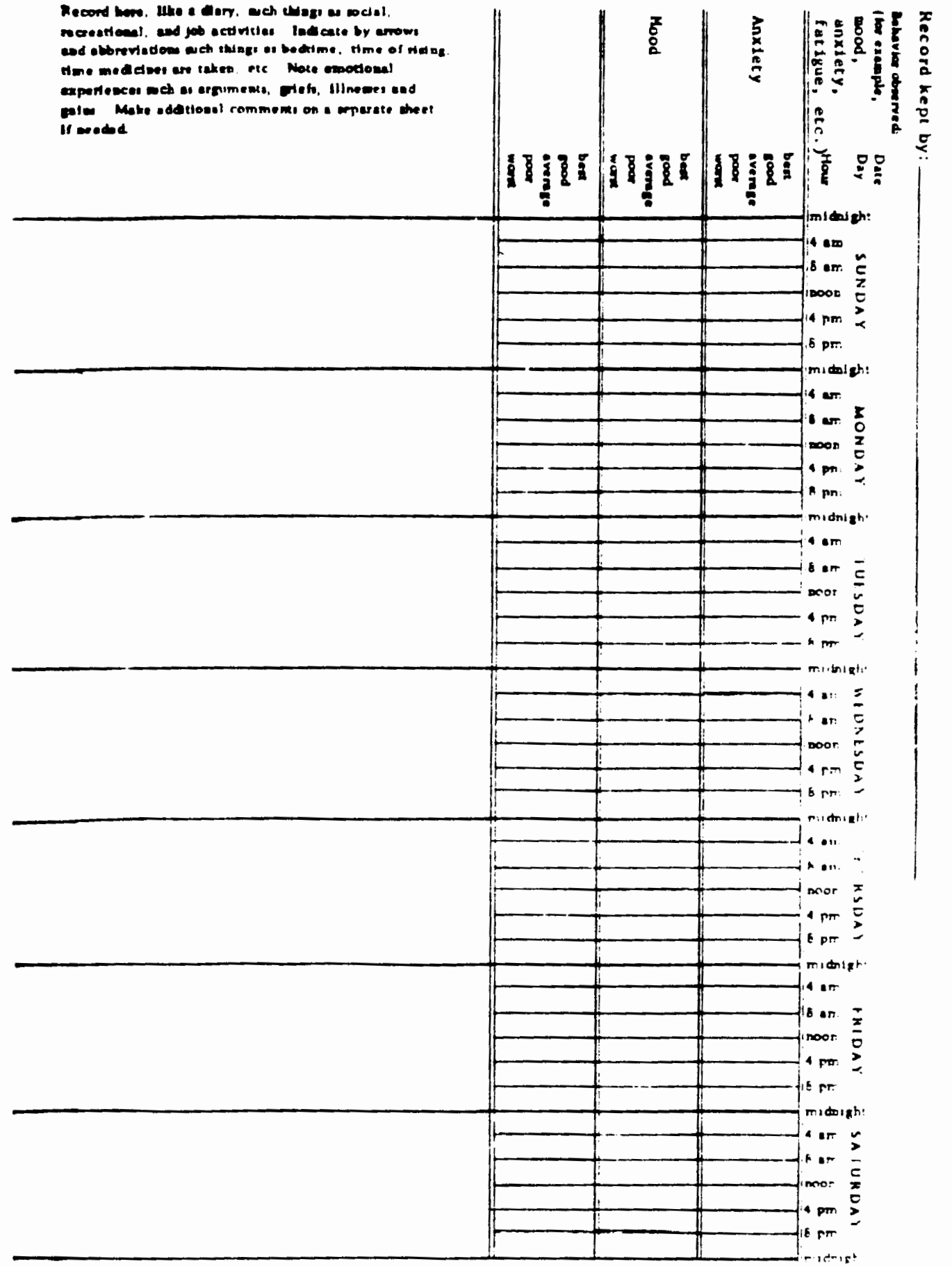
APPENDIX C

SETTING DIAGRAMS

Group Room II

Ward 27 Barnes Hospital VA

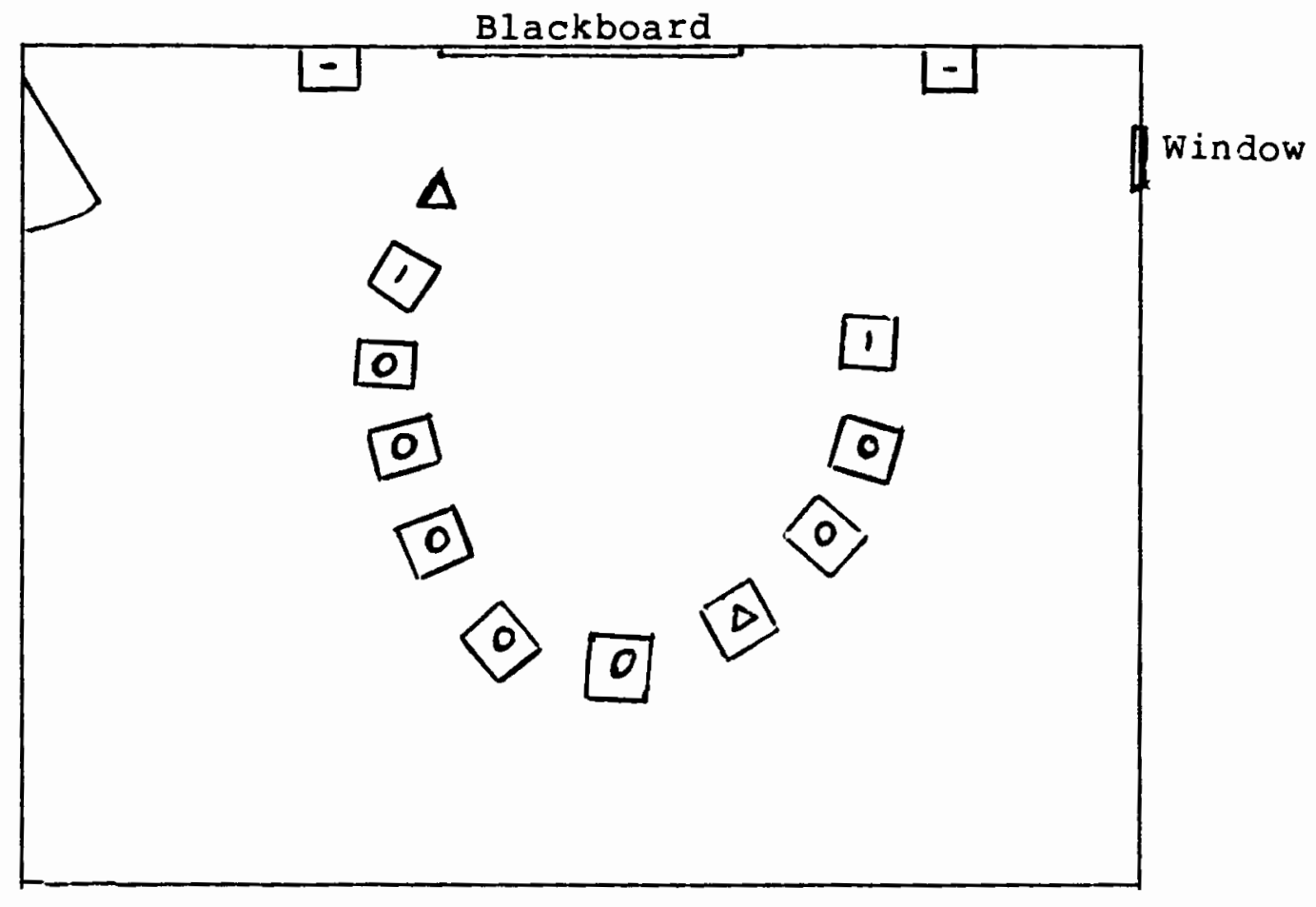

$\Delta$ staff Instructors/Facilitators

O clients

- Unused Chairs 
Observation settings

MHC Reception Area (Portland)

Elevators

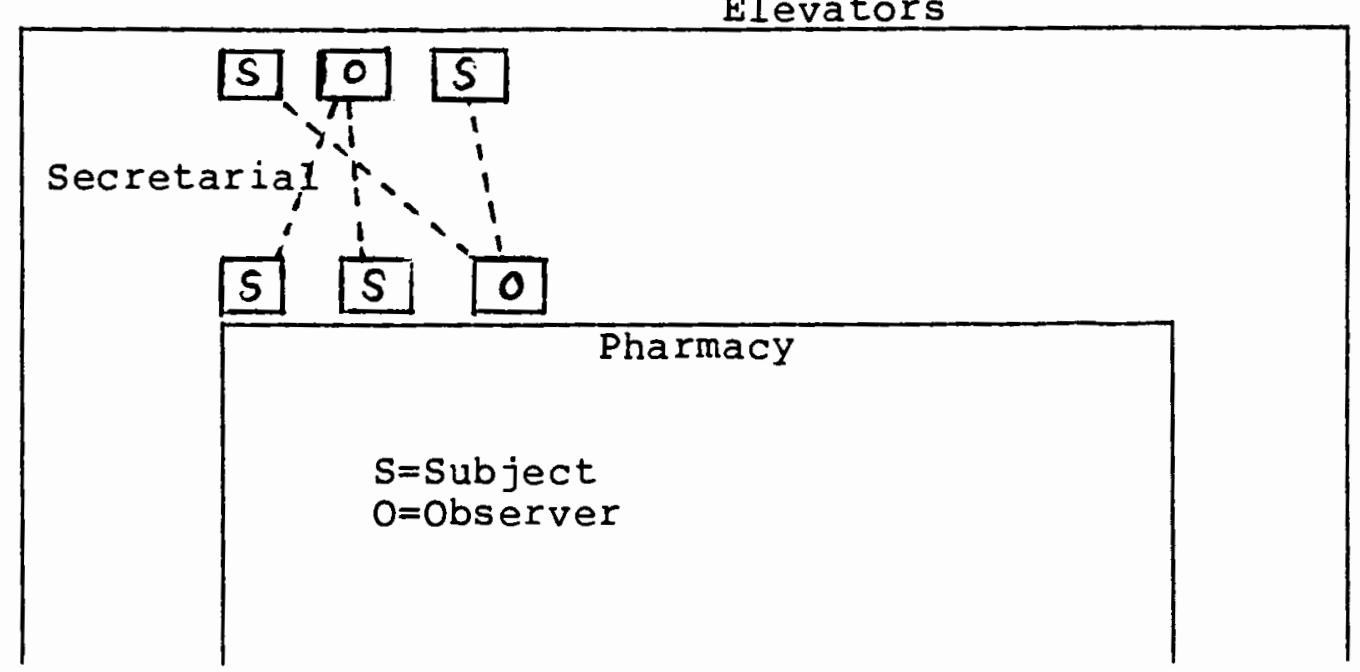

DTC Shuttle Bus

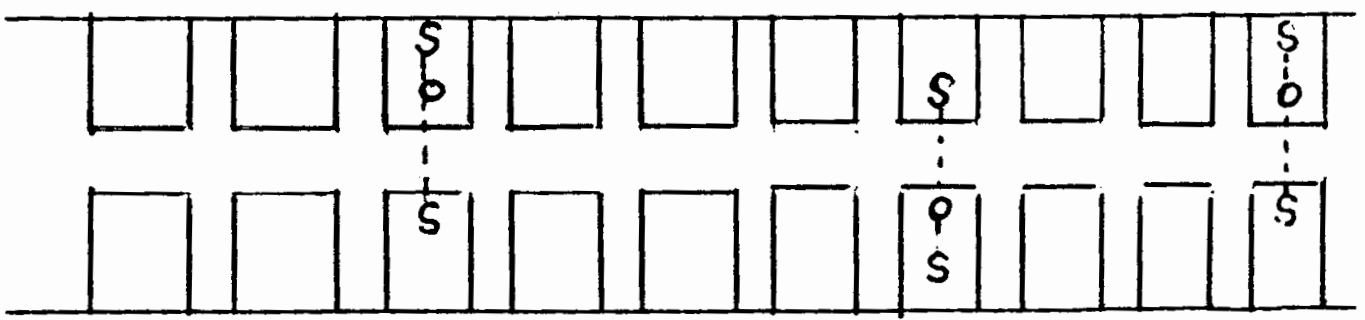

Observer would only observe those directly to one side or the other. 
MHC Clubhouse Area (Vancouver)

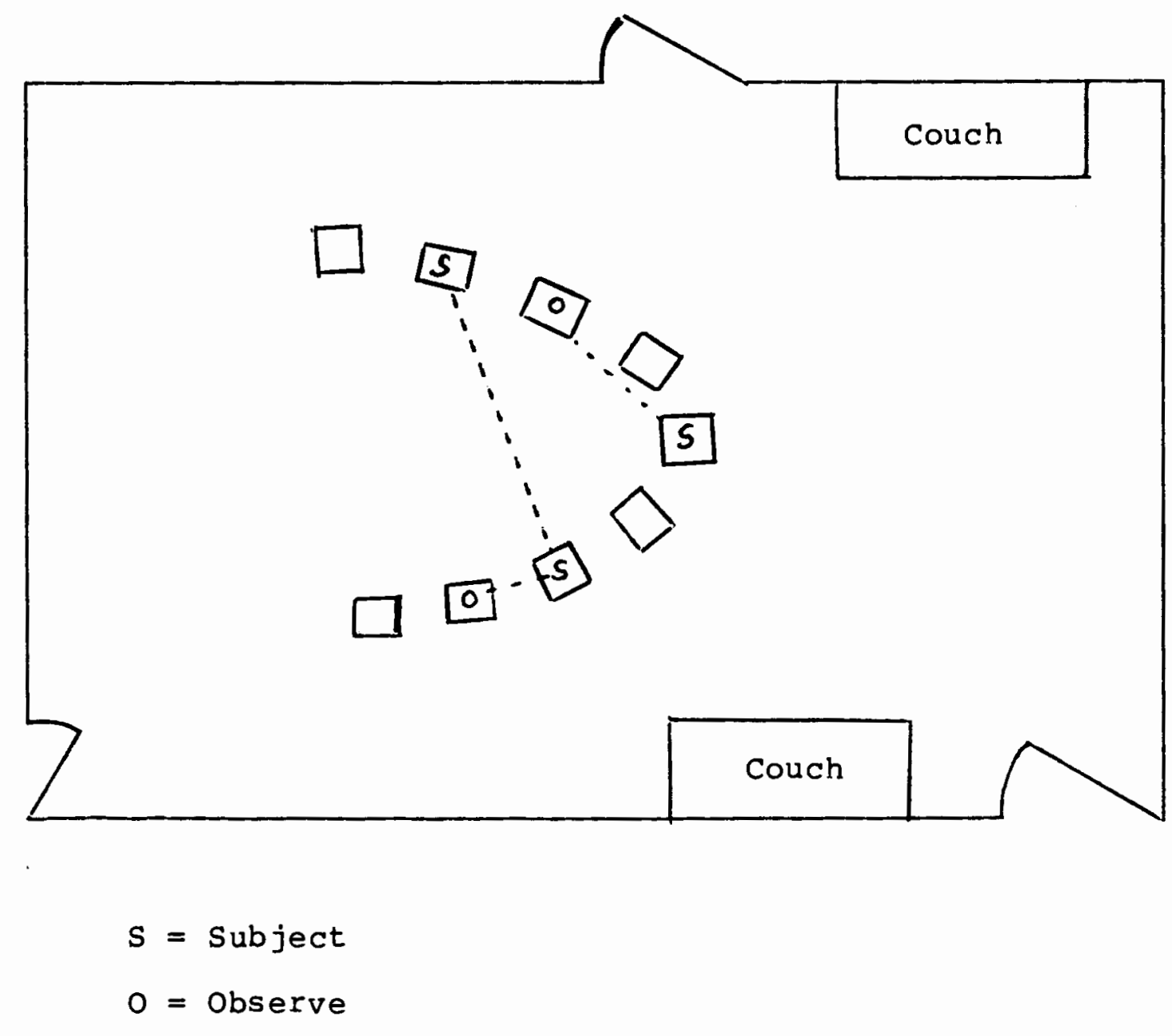


Appendix D

\section{Release of Information Form}

Masanters wi:

CLINICAL RECORD

\section{Repert en}

Comtinuation of S. F.

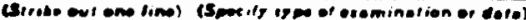

(Sign and dape)

Information About Effect of Stress Management

Instruction and Anxiety Monltoring in Adult Day Treatment Population

We are interested in providing the best care avallable for veterans. In order to find out which is the best care, it 1s often necessary to look at different kinds of care. In th1s study ve are looking for the best was for Day Treatment clients to 1aprove hls/her ab1lity to handle sltuations that may cause nervousness. We are requesting your help in this study to get are inforwation about ho: you cope wth stress. Before you agree to particlpate, ve think it is important for you to understand your rights and privileges.

1) I understand that as a particlpant I may be assigned to one of four groups. Three groups will be asked to participste in different activities relating to coping with atress. One group wll be asked to do a mearingful activity not directly related to copling with stress.

2) I further underatand that, chould one group prove to be more helpful in teaching stress control than another. I wil be given the opportunity to participate fully in that wethod at a later date.

3) I understand I w11I be asked to answer questions at the beginning and end of the Day Ireatment quarter, and $I$ v1ll be asked to answer questlons several months after the study. My answers will help to discover the best wethod for teaching ways of coping with stress.

4) I recognize that my name will in no vay be assoclated with the study, once the results are in and tabulated. In other words ny privacy vill be protected, and only Day Ireatment staff members concerned with wy treatment will be aware of my answers to the questions on the forms. Once the sidy 1 complete and the result: are in, I may go over my answers vith one of the Day Ireatment staff meabers.

5) I also understand that the risks I vill undertake will be no greater than those I as now encountering in regular bay Treatment programsing. In other words, the nature of this ctudy is designed to fit with regular classes in the prograr.

(Continue en reveres aide)

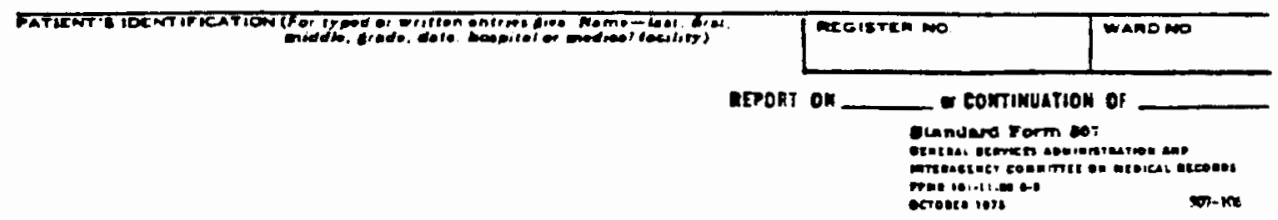

